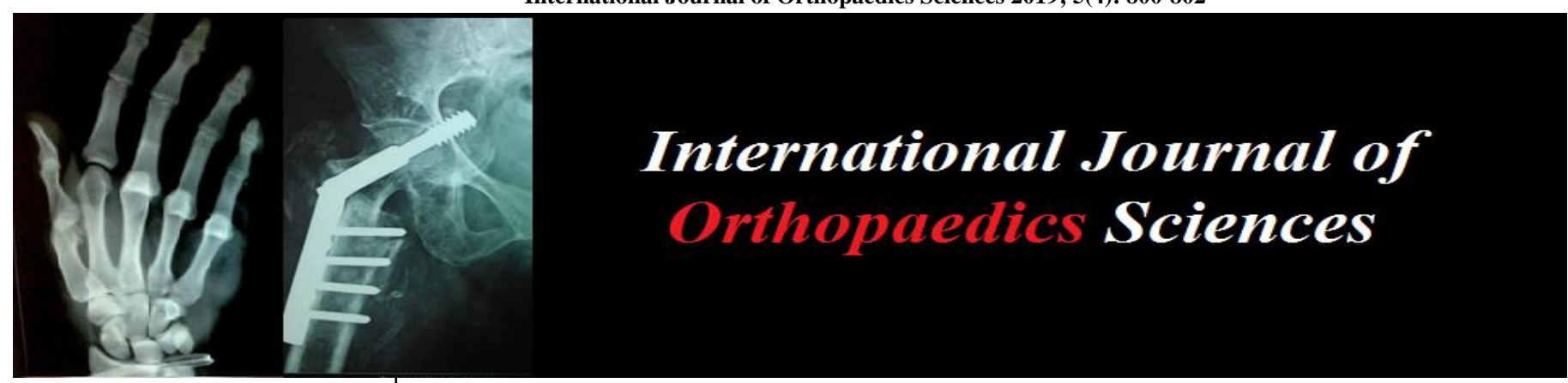

E-ISSN: 2395-1958

P-ISSN: 2706-6630

IJOS 2019; 5(4): 800-802

(C) 2019 IJOS

www.orthopaper.com

Received: 19-08-2019

Accepted: 21-09-2019

Dr. Nagaraj BN

Associate Professor,

Department of Orthopaedics

Akash Institute of Medical

Science and Research Centre,

Bengaluru, Karnataka, India

Corresponding Author:

Dr. Nagaraj BN

Associate Professor,

Department of Orthopaedics

Akash Institute of Medical

Science and Research Centre,

Bengaluru, Karnataka, India

\section{Treatment of acute type 3 acromioclavicular joint dislocation: A prospective study}

\author{
Dr. Nagaraj BN \\ DOI: https://doi.org/10.22271/ortho.2019.v5.i4n.1777
}

\section{Abstract}

The acromioclavicular joint, or AC joint, is a joint at the top of the shoulder. It is the junction between the acromion (part of the scapula that forms the highest point of the shoulder) and the clavicle. It is a plane synovial joint. This was a prospective study where 20 patients attending Outpatient, casualty and patients admitted with acromio clavicular dislocation type III treated conservatively from January to December 2017 were studied. Out of 20 patients 16 had excellent results having no pain or limitation of movements. 3 had good results had mild pain only on excessive activity and terminal restriction of abduction. 1 had fair results and no poor results. Acromioclavicular (AC) dislocation is a common injury especially during road traffic accident. There is still a lack of consensus on whether to conserve or operate type III AC joint dislocations.

Keywords: Acute type 3 acromioclavicular joint dislocation, conservative management

\section{Introduction}

The acromioclavicular joint, or AC joint, is a joint at the top of the shoulder. It is the junction between the acromion (part of the scapula that forms the highest point of the shoulder) and the clavicle. It is a plane synovial joint.

An acromioclavicular joint separation, or AC separation, is a very frequent injury among physically active people. In this injury the clavicle (collar bone) separates from the scapula (shoulder blade). It is commonly caused by a fall directly on the "point" of the shoulder or a direct blow received in a contact sport. Football players and cyclists who fall over the handlebars are often subject to AC separations.

In general, most AC injuries don't require surgery. There are certain situations, however, in which surgery may be necessary. Most patients recover with full function of the shoulder. The period of disability and discomfort ranges from a few days to 12 weeks depending on the severity of the separation. Disruption of the AC joint results in pain and instability in the entire shoulder and arm. The pain is most severe when the patient attempts overhead movements or tries to sleep on the affected side.

Rockwood has classified AC joint dislocation into 6 types. Type I and II are characterised by rupture of acromio clavicular ligaments with loss of horizontal stability. In Type III there is also rupture of coraco-clavicular ligaments with loss of vertical stability, producing dislocation. Rockwood's modification of Sage and Salvatore ${ }^{[2]}$ classification Type III: Acromioclavicular ligaments are disrupted, A.C joint dislocation with shoulder complex displaced inferiorly, Coracoclavicular ligaments are disrupted with increased coracoclavicular interspace (25 to $100 \%$ greater than normal shoulder), and Deltoid and trapezius muscles are usually detached from distal end of clavicle.

Conservative Treatment: Two most commonly used methods are:

1. Closed reduction and application of a sling and harness device to maintain reduction of the clavicle

2. Short term sling support followed by early range of motion.

\section{Objective}

To study the outcome of conservative treatment of type III AC joint dislocation 


\section{Methodology}

\section{Source of data}

This was a prospective study where 20 patients attending Outpatient, casualty and patients admitted with acromio clavicular dislocation type III treated conservatively from January to December 2017 were studied.

\section{Inclusion criteria}

- Men or women $>18$ years age

- AC joint dislocation type III and above

\section{Exclusion criteria}

- AC joint dislocation type I and II

- Men or women $>60$ years of age

- Open dislocation

All patients underwent conservative treatment with adhesive strapping for duration of 3 weeks and rehabilitation by gentle mobilization and graded exercises for next 3 weeks. Patients were followed up at 6 weeks, 3 months and at 6 months.

At each follow up, patients were assessed subjectively for pain, objectively for range of abduction and radio graphically.

\section{Results}

Table 1: Age and Sex wise distribution of cases

\begin{tabular}{|c|c|c|c|}
\hline Age group & Male & Female & Total \\
\hline $10-20$ years & 02 & 01 & 03 \\
\hline $21-40$ years & 08 & 01 & 09 \\
\hline $41-60$ years & 07 & 01 & 08 \\
\hline Total & 17 & 03 & 20 \\
\hline
\end{tabular}

Table 2: Manner wise distribution of cases

\begin{tabular}{|c|c|}
\hline Manner & Number \\
\hline Road traffic accident & 15 \\
\hline Fall from height & 05 \\
\hline
\end{tabular}

Out of 20 patients 16 had excellent results having no pain or limitation of movements.

3 had good results had mild pain only on excessive activity and terminal restriction of abduction. 1 had fair results and no poor results.

Improvement in symptoms were highly significant as per Friedman test value. $(p<0.01)$ Pairwise comparison by wilcoxon signed ranks test showed that the improvement at each follow up was also highly significant except radiologically which did not show significant improvement at the end of 6 months.

\section{Discussion}

Most common age group for A.C. Joint dislocation is 21-40 years. Younger population is usually involved. Complete A.C. Joint dislocation is more common in males compared to females. Most common cause of A.C Joint dislocation was direct trauma to the dome of shoulder usually in high velocity impacts like road traffic accidents or fall from height. At 6 months of follow up after conservative treatment, all patients had significant improvement in range of motion (abduction) which was near normal. Pain reduction was also significant. $2 / 3^{\text {rd }}$ of the patients did not complain of pain while the rest had only mild pain on excessive activity.

M.L Rawes et al. ${ }^{[3]}$ reviewed 30 patients who had been treated conservatively for acromio clavicular dislocation between 1979 and 1982 at an average of $12.5 y$ rs after injury.
All except one had a good out come as did five others contacted by telephone. In all patients reviewed, the acromio clavicular joint remained subluxed or dislocated. With conservative treatment a good long-term outcome can be expected without restoration of anatomical configuration of joint.

Wojtys E.M et al. [4] treated 22 patients with acromio clavicular joint dislocations and evaluated by questionnaire, physical examination, isokinetic strength and endurance testing with mean follow up time of 2.6years. The strength and endurance levels of injured shoulders were comparable to non-injured side. Although discomfort levels were low, long range follow up reports reveal discomfort appearing with increased intensity of activity.

Elif Larsen et al. ${ }^{[5]}$ conducted a prospective, controlled, randomized study of acute acromio-clavicular dislocations where conservative and operative treatment were compared with regard to clinical results, complications, social costs. 41 patients were operated and 43 patients were treated conservatively. Two patients who were operated on and three who were treated conservatively had to have the lateral extremity of clavicle resected because of pain. The rehabilitation period was significantly shorter for nonoperative group and after 13 months there was no difference in clinical results. About half of the patients who were operated on had problems with the metallic device, such as a breakage or migration of pins or both and 6 patients had superficial infection.

Raymond J Imatani ${ }^{[6]}$ and Jon J of naval regional medical center conducted a study in which twenty-three patients with acute, complete acromioclavicular separation were studied prospectively. Twelve patients were treated non-operatively and eleven were treated operatively. A twelve-month minimum follow-up, using a point system to evaluate clinical results, demonstrated comparable results with and without surgery. Roentgenographic findings did not correlate with the clinical results. Minimum immobilization and early rehabilitation of the shoulder was the recommended treatment of choice.

\section{Conclusion}

Acromioclavicular (AC) dislocation is a common injury especially during road traffic accident. There is still a lack of consensus on whether to conserve or operate type III AC joint dislocations. Even among surgeons inclined to operate AC joint dislocations there is no unanimity on which surgical technique. There are a plethora of choices between mechanical fixation or synthetic materials or biologic anatomic reconstructions. Even among surgeons, there is a choice between open repairs and the latest-arthroscopic reconstructions.

\section{Reference}

1. Simon Moyes.co.uk. What is Acromioclavicular Joint Osteoarthritis?. Archived from the original on 2011-0506.

2. Rockwood, Fracture in adults, Injuries to the Acromioclavicular joint.

3. Rawes ML, Dias JJ. Long-term results of conservative treatment for acromioclavicular dislocation. J Bone Joint Surg. 1996; 78B:410-412.

4. Wojtys EM, Nelson G. Conservative treatment of grade III acromioclavicular dislocations. Clin Orthop. 1991; 268:112-119.

5. Larsen E, Bjerg-Nielsen A, Christensen P. Conservative 
or surgical treatment of acromioclavicular dislocation. A prospective, controlled, randomized study. J Bone Joint Surg. 1986; 68A:552-555.

6. Imatani RJ, Hanlon JJ, Cady GW. Acute complete acromioclavicular separation. J Bone joint Surg., 1975; 57A:328-332. 